\title{
Establishment and characterization of a primary canine duodenal epithelial cell culture
}

\author{
Julia L. Golaz • Nathalie Vonlaufen • Andrew Hemphill • \\ Iwan A. Burgener
}

Received: 9 March 2007 / Accepted: 25 April 2007 / Published online: 19 June 2007 / Editor: J. Denry Sato

(C) The Society for In Vitro Biology 2007

\begin{abstract}
Many mechanisms involved in the pathogenesis of chronic enteropathies or host-pathogen interactions in canine intestine have not been elucidated so far. Next to the clinical and in vivo research tools, an in vitro model of canine intestinal cell culture would be very helpful for studies at the cellular level. Therefore, the purpose of this study was to establish and characterize a primary canine duodenal epithelial cell culture. Neonatal duodenum was disrupted with trypsin-ethylenediaminetetraacetic acid (EDTA) and the mucosa scraped off and digested with collagenase and dispase. After centrifugation on a $2 \%$ sorbitol gradient, the cells were incubated at $37^{\circ} \mathrm{C}$ in OptiMEM supplemented with Primocin, epidermal growth factor, insulin, hydrocortisone, and $10 \%$ fetal calf serum (FCS). After $24 \mathrm{~h}$, the FCS concentration was reduced to $2.5 \%$, and the temperature decreased to $33^{\circ} \mathrm{C}$. With this method, the cultures were growing to confluent monolayers
\end{abstract}

Presented in part at the American College of Veterinary Internal Medicine Forum in Louisville, Kentucky, May 31-June 3, 2006.

Julia L. Golaz and Nathalie Vonlaufen contributed equally to this work and are joint first authors. Supported in part by the Vetsuisse research foundation, the Foundation Research 3R (project No. 85/03), and the Swiss National Science Foundation (3100A0-112532).

J. L. Golaz • I. A. Burgener $(\bowtie)$

Department of Clinical Veterinary Medicine,

Division of Small Animal Internal Medicine,

Vetsuisse Faculty of the University of Bern,

Länggassstrasse 122,

3001 Bern, Switzerland

e-mail: iwan.burgener@kkh.unibe.ch

N. Vonlaufen • A. Hemphill

Institute of Parasitology,

Vetsuisse Faculty of the University of Bern,

Länggassstrasse 122,

3001 Bern, Switzerland within 5-6 d and remained viable for an average of $2 \mathrm{wk}$. Their epithelial nature was confirmed by electron microscopy and immunofluorescence staining using antibodies directed against specific cytokeratins, desmosomes, and tight junctions. The intestinal cells proliferated, as evidenced by immunolabeling with a Ki-67 antibody, and cryptal cell subpopulations could be identified. Furthermore, alkaline phosphatase and sucrase activity were detected.

Keywords Dog · Intestine $\cdot$ Neonatal

Chronic enteropathies $\cdot$ Host-pathogen interaction

\section{Introduction}

The gastrointestinal mucosa acts as a barrier between the body and the luminal environment (Colorado State University Web site, Biomedical hypertextbooks: Digestive system. Available at: http://www.vivo.colostate.edu/hbooks/ pathphys/digestion/stomach/gibarrier.html. Accessed March 24, 2006). A simple columnar epithelium covering the surface of the intestinal tube has manifold functions such as assuring the absorption and transport of the nutrients across the cells to the blood, promoting the maintenance of water and electrolyte homeostasis and also acting as a barrier between the body and viruses, bacteria, and parasites that are present in the intestinal lumen.

The normal intestinal epithelium is not inflamed despite the intense contact with commensal organisms, which would elicit inflammatory responses in other parts of the body. Rather than being a passive barrier, it is an active participant in the mucosal immune response through antigen processing and presentation, secretion of cytokines, and recruitment of inflammatory cells in response to 
pathogens and their products (Jung et al. 1995; Savkovic et al. 1997; Hershberg and Mayer 2000). The adjacent gastrointestinal associated lymphoid tissue (GALT) is the largest and most complex immunological organ of the body and must be capable of mounting protective immune response to pathogens, while maintaining tolerance to harmless environmental antigens such as commensal bacteria and food. The breakdown of this tolerance is a key factor in the development of chronic intestinal inflammation in humans and in dogs (Duchmann et al. 1995; German et al. 2003). How these processes are regulated and which factors represent important determinants for maintaining this tolerance has not been elucidated so far.

Canine inflammatory bowel disease (IBD) is among the most commonly encountered chronic enteropathies in dogs, and its manifestations closely resemble human IBD with Crohn's disease and ulcerative colitis (German et al. 2003). The mechanisms involved in the pathogenesis of canine IBD have not yet been defined (Allenspach and Gaschen 2003), so that next to the clinical and in vivo research tools, an in vitro model of canine intestinal cell culture would be very helpful to study defined mechanisms of inflammation at the cellular level. For this, the cultured cells should remain viable, and at the same time, must exhibit phenotypical and functional properties reminiscent to the normal intestinal epithelium. There are only a few nontransformed mammalian intestinal epithelial cell models described that are mostly of rodent origin, and well-characterized canine primary cultures of intestinal epithelium are extremely rare (Swerdlow et al. 2004; Weng et al. 2005). Weng et al. (2005) established monolayers of canine jejunum as model to measure transepithelial voltage and resistance, and Swerdlow et al. (2004) described the expression of pattern recognition receptors TLR2 and 4 and NOD2 in canine colonic epithelial cells without further characterization of the cell culture. Given the fact that in most cases of canine IBD an endoscopy is performed with biopsies taken from the duodenum, it would be highly desirable to have a reliable, well-characterized primary duodenal epithelial cell culture system as an in vitro model for studies on IBD in dogs.

Due to the highly organized and delicately balanced cellular system of the intestine (Kaeffer 2002), there are major difficulties to consider with primary intestinal cell cultures. The epithelial outlining of the gut in vivo is maintained in a dynamic steady state by cells in proliferation, differentiation, and apoptosis along the functional unit, the crypt-villus axis (Perreault and Beaulieu 1998; Kaeffer 2002). This process is tightly regulated by several factors such as hormones, growth factors, cytokines, and interactions between the cells and between the cells and the extracellular matrix (Perreault and Beaulieu 1998). The difficulties in sampling such a tissue arise through the sudden breakdown of blood supply and thermal regulation, the disruption of cell-cell and cell-matrix interactions, and once in culture, the lack of systemic components involved in homeostatic regulation in vivo, particularly the nervous and endocrine system (Kaeffer 2002). The gut stem cells, which are located deep in the crypts, are very sensitive to any changes in their microenvironment, and a deficiency in growth factors or the breakdown of interactions can lead to the induction of apoptosis (Aldhous et al. 2001).

Another challenge for the establishment of a protocol for intestinal epithelial cell culture is the cellular heterogeneity of the tissue that includes epithelial cells of varying ages and differentiation status and other cell types such as fibroblasts and smooth muscle cells. Furthermore, the underlying mesenchyma and its interactions with the epithelium have been described to be necessary to maintain the steady state between epithelial cell proliferation, differentiation, and morphogenesis (Evans et al. 1992; Kedinger et al. 1998; Perreault and Beaulieu 1998).

We here report on the establishment of a primary canine epithelial cell culture model that can now be applied as a tool to study many aspects of intestinal physiology and immunology at the molecular level, including intestinal inflammation and host-pathogen interactions.

\section{Materials and Methods}

Epithelial cell isolation and culture procedure. Tissue samples from 14 clinically healthy neonatal puppies (1-2 d old) that were supernumerous at a laboratory animal breeding facility were taken at necropsy immediately after euthanasia. The entire duodenum $(\sim 10 \mathrm{~cm})$ was excised and collected in ice-cold serum-free culture medium (OptiMEM, GIBCO, Invitrogen AG, Basel, Switzerland) and processed without delay. The duodenum was divided into four pieces, and the segments were cut open longitudinally, washed five times in ice-cold fortified culture medium (FCM), and subsequently disrupted with Trypsin-ethylenediaminetetraacetic acid (EDTA) (GIBCO, Invitrogen AG) for $5 \mathrm{~min}$ at room temperature. The FCM used for these cultures is a commercially available serum-free culture medium (OptiMEM, GIBCO, Invitrogen AG) supplemented with an antibiotic/ antimycotic solution (Primocin, Amaxa GmbH, Köln, Germany; $2 \mu \mathrm{l} / \mathrm{ml})$, murine epidermal growth factor $(20 \mathrm{ng} / \mathrm{ml})$, insulin from bovine pancreas $(10 \mu \mathrm{g} / \mathrm{ml})$, and hydrocortisone 21 hemisuccinate sodium salt $(150 \mathrm{nM})$ (all obtained from Sigma Aldrich Chemie GmbH, Buchs, Switzerland). Each piece of duodenum was then spread on a sterile petri dish, and the luminal surface was scraped gently with a sterile scalpel blade to remove mucus and most of the villi. The scrapings were discarded. Subsequent scrapings leaving only the serosa and part of the muscular layers behind were then collected in a $50-\mathrm{ml}$ tube containing FCM. After centrifugation (2 min, 
$235 \times g, 4^{\circ} \mathrm{C}$ ), the pellet was washed with $\mathrm{FCM}$ and then enzymatically digested with a 1:1 solution of collagenase type I $(0.4 \mathrm{mg} / \mathrm{ml})$ and dispase $(1 \mathrm{mg} / \mathrm{ml})$ (both obtained from GIBCO, Invitrogen AG) for $20-40 \mathrm{~min}$ at $37^{\circ} \mathrm{C}$. To enrich for the crypt cells and to discard most of the detritus and fibroblasts, the remaining pellet was centrifuged twice ( $2 \mathrm{~min}$, $235 \times g, 4^{\circ} \mathrm{C}$ ) on a $2 \%$ sorbitol gradient in FCM supplemented with 2.5\% FCS (AMIMED, Bioconcept, Allschwil, Switzerland). The pellet was finally resuspended with FCM supplemented with $10 \%$ FCS to a density of approximately $5 \times 10^{5}$ cells $/ \mathrm{ml}$. Of this suspension, one milliliter was seeded per well $\left(1.8 \mathrm{~cm}^{2}\right)$ in a 24 -well culture plate with glass cover slips or directly on plastic coated with an extracellular matrix (Matrigel, BD Bioscience, Allschwil, Switzerland). The plate was placed in an incubator at $37^{\circ} \mathrm{C}$ with $5 \% \mathrm{CO}_{2}$ and humidified atmosphere. The medium was changed after $24 \mathrm{~h}$, FCS reduced to $2.5 \%$, and further culturing was done at $33^{\circ} \mathrm{C}$. Thereafter, the medium was renewed every $2 \mathrm{~d}$ for the rest of the remaining culture time. The cultures were inspected every day by light microscopy (Nikon Eclipse TS100, Nikon AG, Nikon Micro Science, Egg, Switzerland) to assess viability, morphology, and proliferation of the cells.

Immunofluorescence labeling. Monolayers of intestinal epithelial cells were grown on glass cover slips in 24-well tissue culture plates. After rinsing with FCM, the cells were fixed in $100 \%$ methanol $\left(7 \mathrm{~min},-20^{\circ} \mathrm{C}\right)$ and permeabilized with phosphate buffered saline (PBS) containing 0.5\% TritonX-100 for $5 \mathrm{~min}$ at room temperature. Blocking was performed with $3 \%$ bovine serum albumin (BSA) in PBS. The primary antibodies (Table 1 ) were diluted in $0.3 \%$ BSA in PBS and incubated with intestinal cells for $1 \mathrm{~h}$ at room temperature. Following three washes in PBS (5 mins each), bound antibodies were detected by incubation of cover slips with the appropriate fluorescein isothiocyanate (FITC) or tetramethyl rhodamin isothiocyanate (TRITC)-conjugated secondary antibodies (Table 2) diluted in $0.3 \%$ BSA in PBS for $30 \mathrm{~min}$ at room temperature. After three additional washes in PBS, the cell nuclei were counterstained with the fluorescent dye Hoechst 33258 (Sigma Aldrich Chemie $\mathrm{GmbH}$ ) diluted 1:300 in $0.3 \%$ BSA in PBS for 2 min at room temperature and rinsed again in PBS. Finally, the coverslips were applied with mounting medium (Fluoprep, Biomérieux, Marcy L'Etoile, France) and the slides dried in an incubator or in ambient air for $5 \mathrm{~min}$. All slides were examined with a fluorescence microscope (Nikon Eclipse E800 digital fluorescence microscope, Nikon AG, Nikon Micro Science, Egg, Switzerland) and digital images were processed using specialized software (Openlab Software Version 2.0.7, Improvision, Heidelberg, Germany).

For occludin and the proliferation marker Ki-67, the procedure described above had to be adapted. For occluding labeling, the cells were fixed in ethanol $\left(30 \mathrm{~min}, 4^{\circ} \mathrm{C}\right)$ followed by acetone $\left(3 \mathrm{~min},-20^{\circ} \mathrm{C}\right)$ and subsequently placed into blocking solution (3\% BSA in PBS). The primary antibody was applied overnight at $4^{\circ} \mathrm{C}$. For labeling of cells with the mouse anti-Ki-67, the cells were only fixed with acetone $\left(10 \mathrm{~min},-20^{\circ} \mathrm{C}\right)$ followed by rehydration with PBS (15 min) and the usual blocking with $3 \%$ BSA in PBS. Thereafter, the cells were incubated with the primary antibody for $2 \mathrm{~h}$ at room temperature.

Western blots. Total cell lysates were obtained by solubilization of the cultured monolayers in $100 \mu$ l sodium dodecyl sulfate-polyacrylamide gel electrophoresis (SDS-PAGE) sample buffer. The lysates were boiled for $5 \mathrm{~min}$ and stored at $-20^{\circ} \mathrm{C}$ before use. After separation of the lysates by $10 \%$ SDS-PAGE, proteins were transferred electrophoretically onto a nitrocellulose membrane. Nonspecific binding-sites were blocked with $3 \%$ BSA in TBS-Tween $(20 \mathrm{mM}$ Tris$\mathrm{HCl}, 150 \mathrm{mM} \mathrm{NaCl}, 0.3 \%$ Tween 20) for $2 \mathrm{~h}$. Immunoblots were then labeled with primary antibodies (Table 1) diluted in $0.3 \%$ BSA in TBS-Tween overnight at $4^{\circ} \mathrm{C}$. Thereafter, antibodies were visualized using the corresponding alkaline phosphatase (AP) conjugates (Table 2) diluted in $0.3 \%$ BSA in TBS-Tween for $1 \mathrm{~h}$ at room temperature according to the instructions provided by the manufacturer.

Scanning electron microscopy. Cell cultures grown on glass cover slips were processed for scanning electron microscopy (SEM) analysis as described by Stettler et al. (2001). Briefly, the cells were fixed in $2.5 \%$ glutaraldheyde in $100 \mathrm{mM}$ sodium cacodylate buffer for $4 \mathrm{~h}$ at room temperature, followed by postfixation in $2 \% \mathrm{OsO}_{4}$ in cacodylate buffer. They were then extensively washed in distilled water, dehydrated in acetone and were sublimation dried (Peldri II, Plano GmbH, Marburg, Germany) in hexamethyldisilazane as described by Hemphill and Croft (1997). Finally, glass cover slips were sputter-coated with gold and inspected on a scanning electron microscope (JEOL 840, JEOL Techniques Ltd., Japan) operating at $25 \mathrm{kV}$.

Transmission electron microscopy. Cultured duodenal epithelial cell monolayers were processed for transmission electron microscopy (TEM) as described by Stettler et al. (2001). Briefly, the cultures were fixed for $4 \mathrm{~h}$ at room temperature in $2.5 \%$ glutaraldehyde in $100 \mathrm{mM}$ sodium cacodylate buffer ( $\mathrm{pH} 7.2$ ), followed by postfixation in $2 \%$ $\mathrm{OsO}_{4}$ in cacodylate buffer. Cells were extensively washed in distilled water and were incubated in $1 \%$ uranyl acetate for $1 \mathrm{~h}$ at $4^{\circ} \mathrm{C}$, followed by several washes in buffer. They were dehydrated in a graded series of ethanol and were subsequently embedded in Epon 812 resin (Shell Chemical Corporation, Cleveland, Ohio) according to the method described by Hemphill and Croft (1997). Polymerization of the resin was carried out at $65^{\circ} \mathrm{C}$ overnight. Sections were cut on a ultramicrotome (Reichert Jung, Wien, Austria) and were loaded onto 300-mesh copper grids (Plano $\mathrm{GmbH}$ ). Staining with uranyl acetate and lead citrate was performed as described by Hemphill and Croft (1997). 
Table 1 Primary antibodies

\begin{tabular}{|c|c|c|c|c|c|}
\hline Antibody & Clone & Specificity & Source & Dilution & Method \\
\hline $\begin{array}{l}\text { Monoclonal mouse } \\
\text { anti-pan-cytokeratin } \\
\text { (mixture) }\end{array}$ & $\begin{array}{l}\text { C-11, PCK-26, CY- } \\
\text { 90, KS-1A3, M20, } \\
\text { A53-B/A2 }\end{array}$ & $\begin{array}{l}\text { Epithelial cells } \\
\text { cytokeratins } \\
1,4,5,6,8, \\
10,13,18,19\end{array}$ & Sigma & $1: 1001: 1000$ & IF WB \\
\hline $\begin{array}{l}\text { Monoclonal mouse } \\
\text { anti-desmosomal } \\
\text { protein }\end{array}$ & ZK-31 & Desmosomes & Sigma & $1: 400$ & IF \\
\hline $\begin{array}{l}\text { Monoclonal mouse } \\
\text { anti-occludin }\end{array}$ & OC-3F10 & Tight junctions & Zymed & $1: 250$ & IF \\
\hline $\begin{array}{l}\text { Monoclonal mouse } \\
\text { anti-vimentin }\end{array}$ & Vim3B4 & Mesenchymal cells & DAKO & $1: 20$ & IF \\
\hline $\begin{array}{l}\text { Goat anti-vimentin } \\
\text { antiserum }\end{array}$ & & Mesenchymal cells & Sigma & $1: 201: 500$ & IF WB \\
\hline $\begin{array}{l}\text { Monoclonal mouse } \\
\text { anti-Ki- } 67 \text { antigen }\end{array}$ & MIB-1 & Proliferating cells & DAKO & $1: 400$ & IF \\
\hline $\begin{array}{l}\text { Monoclonal mouse } \\
\text { anti-Notch } 1\end{array}$ & TS23 & Crypt stem cells & $\begin{array}{l}\text { Proff. Beyenbach } \\
\text { and Quaroni, College } \\
\text { of Veterinary Medicine, } \\
\text { Cornell University, } \\
\text { Ithaca, USA }\end{array}$ & $1: 501: 500$ & IF WB \\
\hline $\begin{array}{l}\text { Polyclonal rabbit } \\
\text { anti-MIM } 1 / 39\end{array}$ & & Crypt cells & $\begin{array}{l}\text { Dr. J.F. Beaulieu, } \\
\text { Anatomy and Cell } \\
\text { Biology, Department } \\
\text { of Medicine, Sherbrooke } \\
\text { University Sherbrooke, } \\
\text { Canada }\end{array}$ & $1: 250$ & IF \\
\hline
\end{tabular}

IF Immunofluorescence, $W B$ Western blot

Brush border enzyme activity. The quantitative assessment of AP activity was performed according to the method described by Stettler et al. (2001). Briefly, culture supernatants were collected at days 2, 4, 6, and 8 of culture and conserved frozen at $-20^{\circ} \mathrm{C}$. After thawing, $50 \mu \mathrm{l}$ of each supernatant was mixed with $150 \mu$ of alkaline phosphatase enzyme-linked immunosorbent assay (ELISA) substrate buffer (0.5 $\mathrm{M}$ ethanolamine and $0.5 \mathrm{mM} \mathrm{MgCl}_{2}, \mathrm{pH} 9.8$ ) containing $p$-nitrophenyl phosphate $(1 \mathrm{mg} / \mathrm{ml})$. The samples were then incubated at $37^{\circ} \mathrm{C}$ for a few minutes until visible coloration changes and $A_{405}$ values were read on an ELISA

Table 2 Secondary antibodies

\begin{tabular}{llll}
\hline Antibody & Source & Dilution & Method \\
\hline Anti-mouse IgG FITC conjugate & Sigma & $1: 100$ & IF \\
Anti-mouse IgG TRITC conjugate & Sigma & $1: 100$ & IF \\
Anti-rabbit IgG FITC conjugate & Sigma & $1: 100$ & IF \\
Anti-goat IgG FITC conjugate & Sigma & $1: 100$ & IF \\
Anti-mouse AP conjugate & Promega & $1: 1000$ & WB \\
Anti-rabbit AP conjugate & Promega & $1: 1000$ & WB \\
Anti-goat AP conjugate & Sigma & $1: 30000$ & WB \\
\hline
\end{tabular}

IF Immunofluorescence, $W B$ Western blot reader (Dynatech MR7000, Dynatech Laboratories Inc., Chantilly, VA).

The sucrase activity was measured according to the method described by Plotkin and Isselbacher (1964) using total cell culture homogenates collected at days 2, 4, 6 and 8 conserved frozen at $-20^{\circ} \mathrm{C}$ before measurement.

\section{Results}

General features of the canine intestinal epithelial cell culture. With the protocol established herein, the primary epithelial cell cultures were growing to confluent monolayers within 5-6 d. Trypsinisation of these monolayers revealed an average of $2 \times 10^{5}$ cells per well. Out of these cells, less than $5 \%$ were fibroblasts as revealed by double labeling with vimentin and cytokeratin. Once the protocol was established, the reproducibility was very high with all 14 cultures yielding similar results.

The enzymatic digestion of the initial scrapings followed by centrifugation on a sorbitol gradient resulted in a suspension containing clumps of epithelial cells, villi, and cryptal fragments with some underlying mesenchymal tissue 
still attached and isolated cells of different origins. The cells were cultured with a density of $\sim 5 \times 10^{5}$ cells $/ \mathrm{ml}$ and an average of 24 wells could be seeded each time. At the first culture medium change after $24 \mathrm{~h}$, the cells showed a good attachment to the substrate, particularly the cells of the smaller, still structured fragments (Fig. 1a). The nonattached material, composed of isolated cells, larger cell clumps (mostly in degeneration), and detritus, was washed away. The attachment of the cells to matrigel-coated wells was generally more efficient compared to uncoated wells, but not essential for further development of the monolayers. The cells at the border of the adherent tissue fragments started to spread out and migrate. After the incubation temperature was changed to $33^{\circ} \mathrm{C}$, significant proliferation of these cells was observed by light microscopy during at least 4 to $5 \mathrm{~d}$. The monolayers were confluent after 5-6 d (Fig. 1b), and at this stage, the intestinal epithelial cells (IEC) could be subcultured without loosing the phenotypical proprieties and proliferation capacity. However, the proliferation seized or was strongly diminished after the second passage, and mesenchymal cells overgrew the culture. The IEC were viable and could be maintained and studied for an average of $2 \mathrm{wk}$. After $10 \mathrm{~d}$, the proportion of degenerative IEC started to increase, and mesenchymal cells grew more rapidly. Although some epithelial cells were still viable after $3 \mathrm{wk}$, the monolayer was not continuous anymore, and the cell phenotype as observed by light microscopy became more and more heterogeneous.

Immunofluorescence labeling demonstrates expression and localization of epithelial cell markers. The epithelial nature of the monolayers was confirmed by specific labeling of the epithelial cytoskeletal intermediate filaments with an anti-pan-cytokeratin antibody, which recognizes a range of cytokeratins $(1,4,5,6,8,10,13,18$, and 19) (Fig. 2a-b). The tight junction-specific protein occludin and desmosomes were both detected using respective specific antibodies, which labeled the cell-cell contacts in the intercellular regions of the confluent IEC monolayer (Fig. $2 c-d$ ). Furthermore, proliferating epithelial cells could be identified by double staining with anti-pan-cytokeratin antibody and an antibody against the cell proliferation marker $\mathrm{Ki}-67$. Ki-67 is a nuclear protein expressed during all active phases of the cell cycle but not in quiescent cells (Fig. 2e) (Pageot et al. 2000; Engelhardt et al. 2005; Saiwaki et al. 2005). Based on the fact that Ki-67 protein is associated with the cell chromatin and there is a differential expression pattern during different phases of the cell cycle (Saiwaki et al. 2005), a basic differentiation between cells in mitosis and cells in interphase could be made. Cells in interphase yielded mostly a nucleolar staining pattern, whereas in mitotic cells, the protein was relocated to the chromosomal periphery and sometimes also stained the cytoplasm (Fig. 2e). Staining with the monoclonal antibody TS23 specific for a glycosylated form of Notch-1, a protein expressed in human and rat intestinal stem cells (Weng et al. 2005), indicated that crypt stem cells were mainly localized in the center and at the border of the adherent tissue units, from which the cells finally forming the monolayer actually originated (Fig. $2 f$ ). The same staining pattern was observed with an antibody against MIM 1/39, a 350-kDa glycoprotein normally found in the apical portion of epithelial crypt cells of small intestine in humans and mice (data not shown) (Perreault and Beaulieu 1996, 1998; Pageot et al. 2000).

Analysis of epithelial-specific intermediate filament expression by immunoblotting. Western blots (WB) of total cell lysates were used to analyze the expression pattern of the intermediate filament proteins among the range of cytokeratins recognized by the pan-anti-cytokeratin antibody. These blots demonstrated that the IEC express mostly cytokeratin 8 and 18 (Fig. $3 a$ ). The detection of the protein vimentin, an intermediate filament protein expressed in

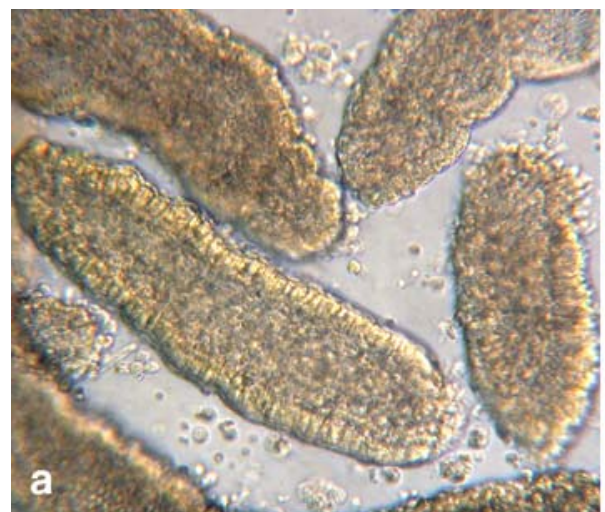

Figure 1 Microscopical pictures of a primary duodenal cell culture. Microscopical pictures of a primary duodenal cell culture just after seeding $(a)$ and of a confluent monolayer after 7 days $(b)$. The obtained suspension seeded in the culture plates contains villi and/or

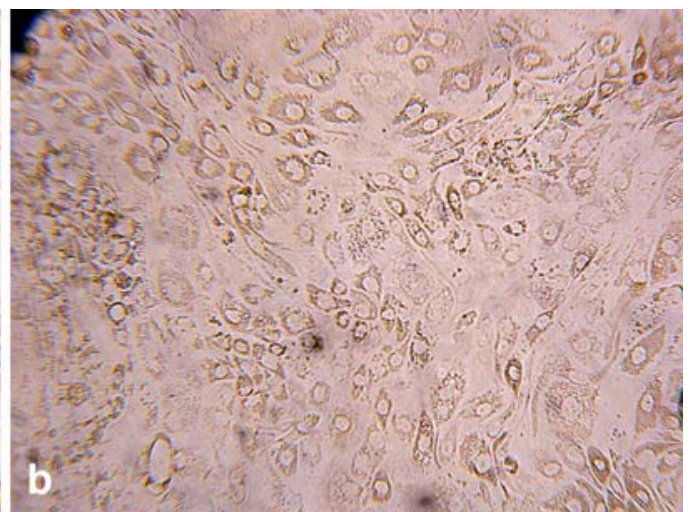

cryptal fragments constituted of an epithelial outlining and a mesenchymal core and some isolated cells. After 5-6 d of spreading and proliferation, the epithelial cells are forming a dense confluent monolayer. 

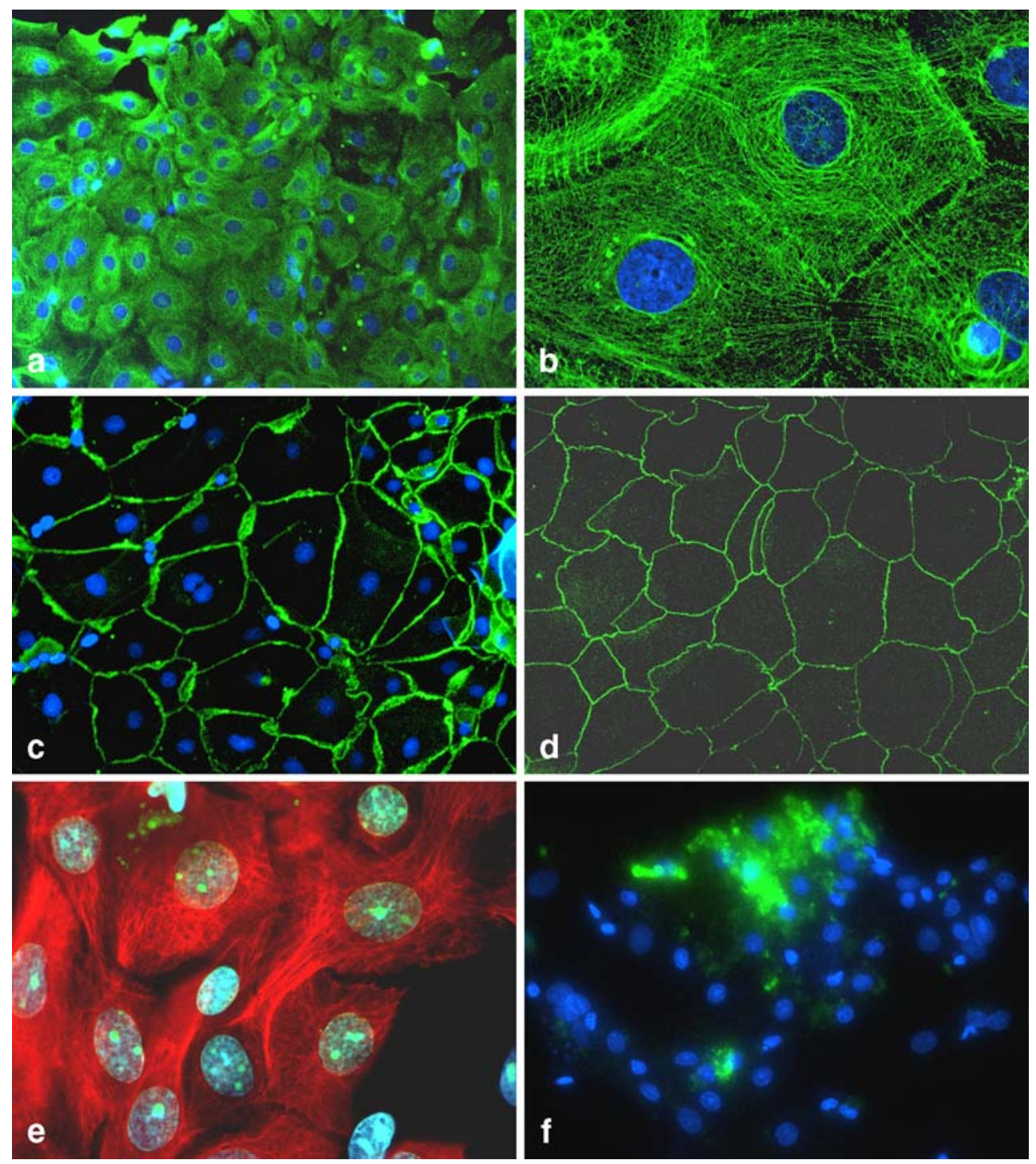

Figure 2 Characterization of the cell line with immunofluorescence labeling. FITC-labeling of cytokeratins after $5 \mathrm{~d}$ of culture at magnification $10(a)$ and $40(b)$. FITC-labeling of the tight junctionassociated protein occludin $(c)$ and desmosomes $(d)$. With a magnification of 10 , occludin is visible as a fine pericellular band outlining the confluent intestinal epithelial cells and desmosomes present as a larger continuous band putting in evidence the pericellular space. Double staining with a monoclonal mouse anti-Ki-67 (secondary antibody FITC-conjugated) and a monoclonal mouse anti-pan-cytokeratin antibody (secondary antibody TRITC-conjugated) (e). The nuclear

connective tissue and thus also in fibroblasts, was also analyzed and compared to human foreskin fibroblasts as positive control (Fig. 3b). Vimentin was only weakly expressed in the duodenal cultures, but highly expressed in fibroblasts. Therefore, contamination of the primary cultures with other cells, essentially fibroblasts, could not be totally avoided but could be maintained at a very low level. This semiquantitative estimation was confirmed by light microscopy and immunofluorescence double labeling with vimentin and cytokeratin, where the proportion of fibroblasts in the

protein Ki-67 associated with the cell chromatin reveals the proliferating epithelial subpopulations. Cells in interphase show a nucleolar staining pattern, whereas the protein is relocated to the chromosomal periphery in mitotic cells. FITC-labeling with the crypt stem cell marker Notch-1 (clone TS23) $(f)$. This staining indicated that the crypt stem cells were mostly present in the center and on the border of the adherent tissue units. Cell nuclei are counterstained with Hoechst 33258 nuclear stain. All figures show the outcome of one experiment out of at least three performed, all with virtually identical results.

primary cultures was not exceeding $5 \%$ during the first $10 \mathrm{~d}$ of culture.

Scanning electron microscopy and transmission electron microscopy. The IEC monolayers showed an epithelial morphology with microvilli facing the culture medium and infoldings of the basolateral membrane as demonstrated with the help of TEM and SEM (Fig. 4). Tight junctions shown by immunostaining of the associated protein occludin were also visible by TEM (Fig. 4e). Furthermore, TEM yielded a subpopulation of cells with prominent granules in the 
cytoplasm, which could also be identified by light microscopy (Fig. $4 f$ ). These cells could possibly be goblet cells (Weng et al. 2005).

Brush border enzymes activity. Besides the morphological and structural properties of the IEC primary cultures, some functional characteristics were assessed by measuring the activity of the brush border enzymes alkaline phosphatase in culture supernatants at days 2, 4, 6, and 8 after seeding. Activity was detected in all samples and was highest at day 2 , while decreasing over time, approaching zero at day 8 . Sucrase activity was also detected in cell culture homogenates at day $2,4,6$, and 8 without significant variation over time (data not shown).

\section{Discussion}

Given the incomplete understanding of the pathogenesis of several canine intestinal diseases like IBD and the hostpathogen interaction for some gastrointestinal parasites, the necessity for a canine intestinal cell culture model is obvious. This model should resemble the normal intestinal barrier as much as possible to study the mechanisms of inflammation and interaction at a cellular level. Fully differentiated epithelial cells derived from the normal mammalian intestine are difficult to culture in vitro (Quaroni and Hochman 1996) and well-characterized primary intestinal epithelial cell cultures of canine origin are extremely rare (Swerdlow et al. 2004; Weng et al.

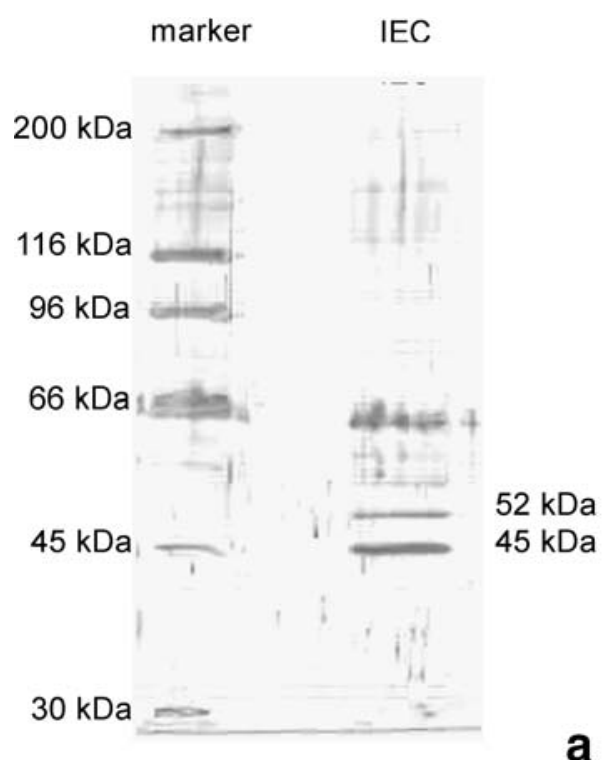

Figure 3 Western blot analysis of total cell lysate. Western blot analysis of total cell lysate of intestinal epithelial cells (IEC) at day 6 for cytokeratins $(a)$ and vimentin $(b)$. Among all cytokeratins recognized by the anti-pan-cytokeratin antibody, particularly cytokeratins 8 (band at $52 \mathrm{kDa}$ ) and 18 (band at $45 \mathrm{kDa}$ ) were expressed. The
2005). Weng et al. (2005) established monolayers of canine jejunum as model to measure transepithelial voltage and resistance, and Swerdlow et al. (2004) described the expression of pattern recognition receptors TLR2 and 4 and NOD2 in canine colonic epithelial cells without further characterization of the cell culture. Given the fact that in most cases of canine IBD an endoscopy is performed with biopsies taken from the duodenum, it would be highly desirable to have a reliable, well-characterized primary duodenal epithelial cell culture system as an in vitro model for studies on IBD in dogs.

Before establishing the protocol described herein with neonatal tissue, there were many assays performed with duodenal biopsies from adult dogs taken at routine endoscopical examination in our clinic. The results obtained were somehow heterogeneous and never really satisfying concerning the viability and proliferation properties. Nevertheless, these assays permitted us to develop, compare, and optimize different techniques of cell isolation, culture conditions, and culture medium composition found in the literature with regard to intestinal cell cultures of human (Perreault and Beaulieu 1996; Panja 2000; Aldhous et al. 2001), rodent (Evans et al. 1992), bovine (Föllmann et al. 2000), and canine (Swerdlow et al. 2004; Weng et al. 2005) origin. Given the presumed higher proliferation capacity of neonatal intestine (Evans et al. 1992; Quaroni and Hochman 1996; Grossmann et al. 2003; Wong, 2004), the procedure was then transferred onto neonatal tissue and optimized under these conditions.

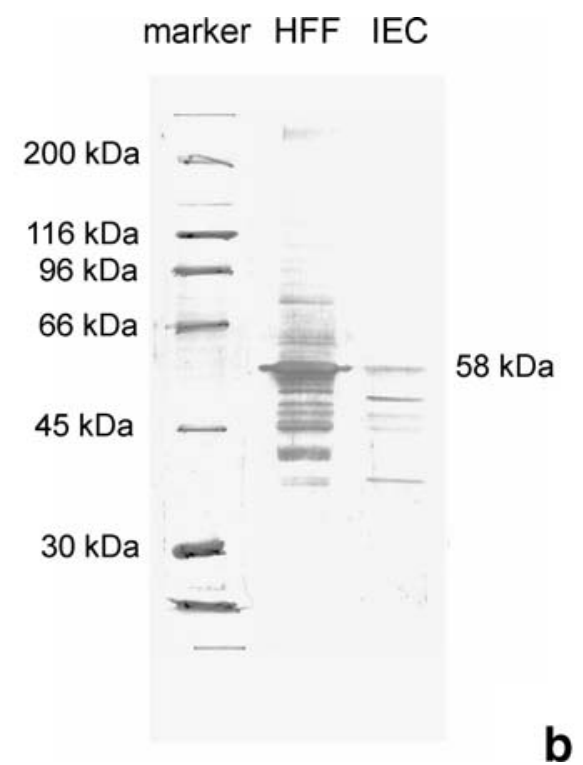

vimentin expression of IEC was compared with a positive control made of human foreskin fibroblasts (HFF). The low expression of vimentin in the primary IEC cultures confirmed low contamination with fibroblasts. These Western blots show the outcome of one experiment out of three performed, all with virtually identical results. 
Figure 4 Characterization of the cell line with electron microscopy. Scanning electron micrographs $(a-b)$ and transmission electron micrographs $(c-f)$ from confluent monolayers of intestinal epithelial cells. The monolayer surface is flat with an apical microvilli layer showing variations in density $(a-d)$. The cells are in very close contact with membrane infoldings $(d-e)$ and junctions $(e)$ binding them together. A subpopulation of cells showing prominent granules in the cytoplasm were identified $(f)$. These cells could possibly be goblet cells. All figures show the outcome of one experiment out of at least three performed, all with virtually identical results.
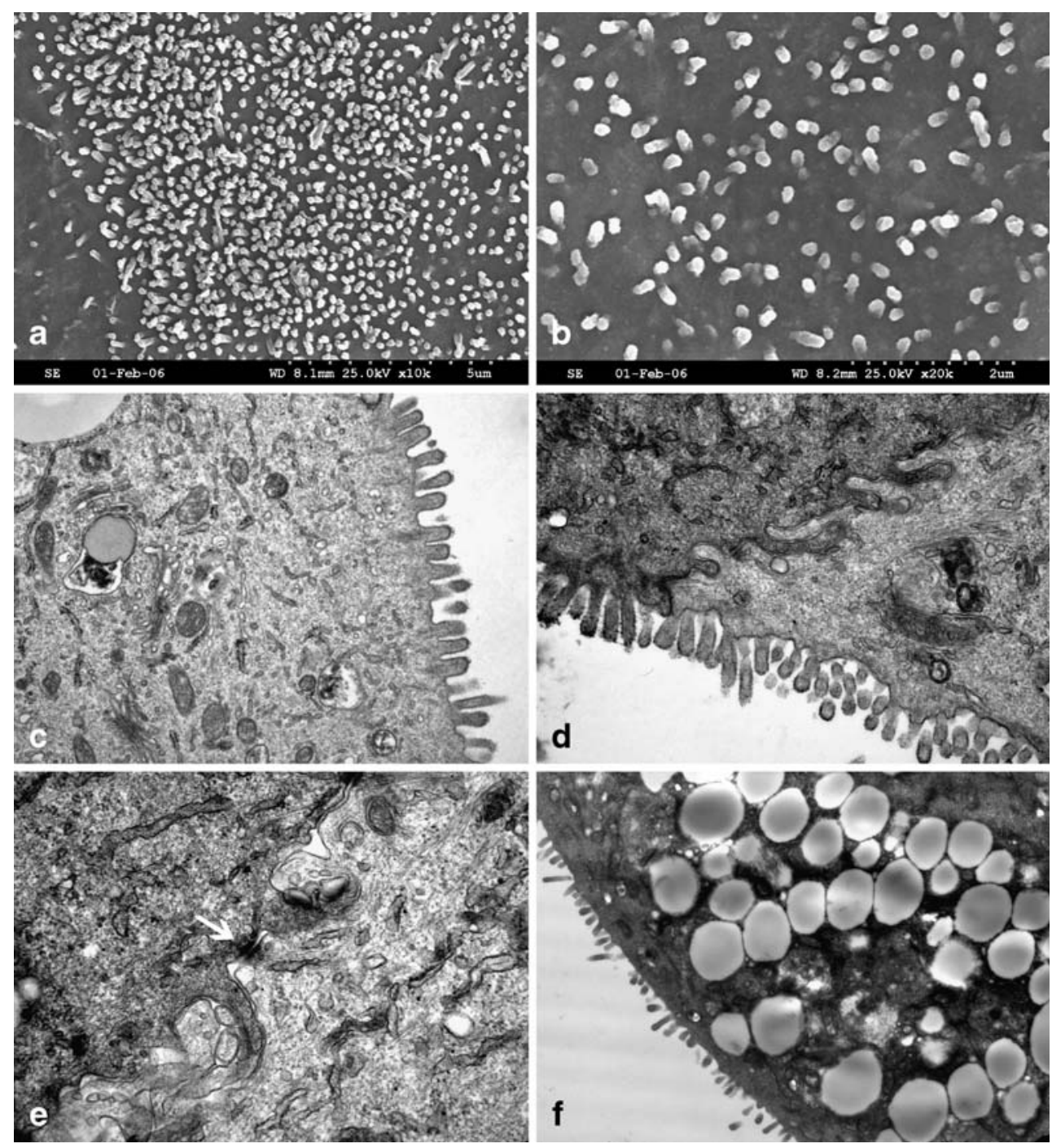

During optimization of the protocol, various problems had to be considered. The intestinal epithelial barrier as a highly organized and delicately balanced cellular system (Kaeffer 2002) is influenced by several factors, interactions, and multiple signaling pathways. By sampling such a tissue, the breakdown of blood supply and the disruption of cell-cell and cell-extracellular matrix interactions can induce apoptosis. The method used is combining multiple tools to gently and efficiently isolate the epithelial cells out of the tissue, like enzymatic digestion with trypsin and collagenase/ dispase, two steps of mechanical scraping of the intestinal mucosa, and finally, the use of a $2 \%$ sorbitol gradient to discard single cells (Föllmann et al. 2000). Beside the maintenance of the viability during the sampling and isolation procedure, there is a necessity to have a proliferating cell pool among the IEC seeded in the culture plates to support the growth until a confluent monolayer is reached. Considering the organization of the adult small intestine in vivo (Wong 2004), we can assume that a portion of the starting material in the primary cultures is of cryptal origin.
This assumption was proven by positive immunostaining with antibodies directed against two different markers for intestinal crypt cells [Notch-1 (Weng et al. 2005), MIM 1/39 (Perreault and Beaulieu 1996, 1998; Pageot et al. 2000)]. Furthermore, the cryptal origin was proven by a Western blot analysis for cytokeratins that revealed the presence of cytokeratins 8 and 18 , with a larger band at $45 \mathrm{kDa}$ for cytokeratin 18. It has been shown by in situ hybridization in rats that the distribution of cytokeratin 18 is restricted to the region of the crypts in the adult intestine and strictly confined at the base of the nascent villi by the prenatal developing intestine, whereas cytokeratin $8 \mathrm{mRNA}$ is expressed by the entire epithelium in both situations (Calnek and Quaroni 1993). Conceding that this distribution and expression pattern can be conferred on other mammals, the majority of the cytokeratin found in our cultures is coming from cryptal cells, or more precisely, from cells of the intervillus region with the intestine still in development.

The primary cultures described in this study were started with neonatal tissue explants from 1- to 2-d-old puppies. 
Taking the murine intestinal development as a reference, it is known that the intervillus region contains several active multipotent stem cells (Wong 2004) that convert into crypts within the first $2 \mathrm{wk}$, and this process increases rapidly during the third week (Hauck et al. 2005). During this conversion, the stem cells undergo a reduction from putative multiple stem cells to a single or few stem cells per mature crypt (Wong 2004). This fact implies that at the moment of the tissue processing for the culture, the mucosa of the samples is probably composed of villi and intervillus regions, housing more stem cells than in adult tissue. With this in mind, the two steps scraping technique allows to discard most of the villi and to keep the proliferating intervillus region for the culture seeding. This step is important for the development of the confluent monolayers within 5 to $6 \mathrm{~d}$.

The factors and interactions that support proliferation and differentiation of the immature cells and contribute to the structural organization of the gut mucosa in vivo are multiple and complex. Interactions between the epithelial cells themselves and with the underlying mesenchymal tissue and extracellular matrix components are using multiple signaling pathways and paracrine factors which are known to be critical (Wong 2004; Fre et al. 2005; Hauck et al. 2005). Besides the supplementation of the culture medium with stimulating factors like epidermal growth factor and insulin, a certain cellular heterogeneity with maintenance of integrity and organization of the tissue in vitro would be very useful for the development of functional cells. A mesenchymal core or underlying layer in the starting material is therefore an advantage to develop a model resembling the reality. On the other hand, the growth of this cell pool should be maintained as low as possible to prevent an overgrowth of the IEC. By using the sorbitol gradient technique during isolation (Föllmann et al. 2000), detritus, isolated epithelial cells, and fibroblasts were discarded. Furthermore, the reduction of the FCS concentration to $2.5 \%$ after $24 \mathrm{~h}$ inhibited an overgrowth with the remaining mesenchymal cells (Evans et al. 1992). By means of immunofluorescence double labeling with vimentin and cytokeratin, the proportion of fibroblasts in the primary cultures was found to be less than $5 \%$ during the first $10 \mathrm{~d}$ of culture. The $10 \% \mathrm{FCS}$ in the culture medium during the first $24 \mathrm{~h}$ was required to optimize the attachment of the IEC on the substrate. Given the fact that FCS contains growth factors from the epidermal growth factor and insulin families (Kaeffer 2002), the culture medium had to be supplemented with corresponding substances to selectively stimulate the growth of epithelial cells after reducing FCS from 10 to $2.5 \%$.

To be a representative model, the IEC in culture should also demonstrate differentiation characteristics of functional enterocytes and not only contain immature cells with proliferating capacity. In vivo, there is a perpetual balance between immature proliferating cells and cells that differentiate to become functional and finally are expulsed in the intestinal lumen. The turnover is high, and the whole procedure takes only $3-5$ d. Hydrocortisone is described to promote the differentiation of the cells, the apparition of tight junctions, the formation of microvilli, and the reorganization of the cell organelles, but also to inhibit the cell growth after 4-7 d in a concentration-dependent matter (Quaroni et al. 1999). With the addition of hydrocortisone to our culture medium, we tried to find a balance between proliferation and differentiation in the cell culture. The obtained monolayers of IEC are developing ultrastructural components typical for a polarized epithelium. The microvilli on the apical membrane and tight junctions and desmosmes between the neighboring cells demonstrate a certain differentiation status of the IEC and recovered tissue integrity. The brush border shown in TEM and SEM pictures is made of small microvilli with a lower density as in adult intestine, probably due to the neonatal origin of the cells. Furthermore, functional differentiation of primary epithelial cells was determined by detection of brush border AP and sucrase activity. In addition, TEM yielded a subpopulation of cells with cytoplasmatic vacuoles that closely resemble goblet cells (Weng et al. 2005).

In summary, we conclude that neonatal canine duodenal epithelial cells can be cultured and may serve as a useful model for further studying of the pathogenesis of IBD, certain aspects of host-pathogen interaction, and many other gastrointestinal diseases. The characteristics of the neonatal cultures described herein (and several cultures performed since then) are very similar, which makes this primary cell culture model a good and reproducible model with many characteristics resembling the intestinal barrier in vivo. Furthermore, the average life span of $2 \mathrm{wk}$ is giving us the possibility to study certain effects during proliferation and differentiation of the IEC.

Acknowledgments The authors would like to thank Prof. Beyenbach and Prof. Quaroni for providing the monoclonal antibody TS23 specific to the glycosylated form of Notch-1 and Dr. Herring and Prof. Beaulieu for providing the MIM 1/39 antibody, an intestinal crypt cell marker. Furthermore, the authors would like to acknowledge Ursula Luginbühl for sucrase activity measurement, and many thanks are addressed to Eliane Mueller for advice in immunofluorescence staining.

\section{References}

Aldhous, M. C.; Shmakov, A. N.; Bode, J., et al. Characterization of conditions for the primary culture of human small intestinal epithelial cells. Clin. Exp. Immunol. 125:32-40.2001.

Allenspach, K.; Gaschen, F. Chronic intestinal diseases in the dog: a review. Schweiz. Arch. Tierheilkd. 145(5):209-219, 221-2.2003. 
Calnek, D.; Quaroni, A. Differential localization by in situ hybridization of distinct keratin mRNA species during intestinal epithelial cell development and differentiation. Differentiation 53:95-104.1993.

Duchmann, R. I.; Kaiser, E.; Hermann, W., et al. Tolerance exists towards resident intestinal flora but is broken in active inflammatory bowel disease (IBD). Clin. Exp. Immunol. 102:448-455.1995.

Engelhardt, P.; Wyder, M.; Zurbriggen, A., et al. Canine disempter virus associated proliferation of canine footpad keratinocytes in vitro. Vet. Microbiol. 107:1-12.2005.

Evans, G. S.; Flint, N.; Somers, A. S., et al. The development of a method for the preparation of rat intestinal epithelial cell primary cultures. J. Cell Sci. 101:219-231.1992.

Föllmann, W.; Weber, S.; Birkner, S. Primary cell cultures of bovine colon epithelium: isolation and cell culture of colonocyte. Toxicol. In Vitro 14:435-445.2000.

Fre, S.; Huyghe, M.; Mourikis, P., et al. Notch signals control the fate of immature progenitor cells in the intestine. Nature 435:964968.2005.

German, A. J.; Hall, E. J.; Day, M. J. Chronic intestinal inflammation and intestinal disease in dogs. J. Vet. Intern. Med. 17:8-20.2003.

Grossmann, J.; Walther, K.; Artinger, M., et al. Progress on isolation and short-term ex-vivo culture of highly purified non-apoptotic human intestinal cells (IEC). Eur. J. Cell. Biol. 82:262-270.2003.

Hauck, A. L.; Swanson, K. S.; Kenis, P. J. A., et al. Twists and turns in the development and maintenance of the mammalian small intestine epithelium. Birth Defects Res C Embryo Today 75:5871.2005.

Hemphill, A.; Croft, S. L. Electron microscopy in parasitology. In: Rogan, M. ed. Analytical parasitology. Springer Verlag, Heidelberg, Germany; 1997:227-268.

Hershberg, R. M.; Mayer, L. F. Antigen processing and presentation by intestinal epithelial cells - polarity and complexity. Immunol. Today 21:123-128.2000.

Jung, H. C.; Eckmann, L.; Yang, S. K., et al. A distinct array of proinflammatory cytokines is expressed in human colon epithelial cells in response to bacterial invasion. J. Clin. Invest. 95:5565.1995 .

Kaeffer, B. Mammalian intestinal epithelial cells in primary culture: a mini-review. In Vitro Cell Dev. Biol. Anim. 38:123-134.2002.

Kedinger, M.; Duluc, I.; Fritsch, C., et al. Intestinal epithelialmesenchymal cell interactions. Ann. N Y Acad. Sci. 859:1-17.1998.
Pageot, L. P.; Perreault, N.; Basora, N., et al. Human cell models to study small intestinal functions: recapitulation of the crypt-villus axis. Microsc. Res. Tech. 49:394-406.2000.

Panja, A. A novel method for the establishment of a pure population of nontransformed human intestinal primary epithelial cell (HIPEC) lines in long term culture. Lab. Invest. 80:1473-1475.2000.

Perreault, N.; Beaulieu, J. F. Use of the dissociating enzyme thermolysin to generate viable human normal intestinal epithelial cell cultures. Exp. Cell Res. 224:354-364.1996.

Perreault, N.; Beaulieu, J. F. Primary cultures of fully differentiated and pure human intestinal epithelial cells. Exp. Cell. Res. 245:34-42.1998.

Plotkin, G. R.; Isselbacher, K. J. Secondary disaccharidase deficiency in adult celiac disease (nontropical sprue) and other malabsorption states. New Engl. J. Med. 271:1033-1037.1964.

Quaroni, A.; Hochman, J. Development of intestinal cell culture models for drug transport and metabolism studies. Adv. Drug Deliv. Res. 22:3-52.1996.

Quaroni, A.; Tian, J. Q.; Göke, M., et al. Glucocorticoids have pleiotropic effects on small intestinal crypt cells. Am. J. Physiol. Gastrointest. Liver Physiol. 277:G1027-G1040.1999.

Saiwaki, T.; Kotera, I.; Sasaki, M., et al. In vivo dynamics and kinetics of pKi-67: transition from a mobile to an immobile form at the onset of anaphase. Exp. Cell Res. 308:123-134.2005.

Savkovic, S. D.; Koutsouris, A.; Hecht, G. Activation of NF-kappaB in intestinal epithelial cells by enteropathogenic Escherichia coli. Am. J. Physiol. 273:C1160-C1167.1997.

Stettler, M.; Siles-Lucas, M.; Sarciron, E., et al. Echinococcus multilocularis alkaline phosphatase as a marker for metacestode damage induced by in vitro drug treatment with albendazole sulfoxide and albendazole sulfone. Antimicrob. Agents Chemother. 45:2256-2262.2001.

Swerdlow, M.; Kennedy, D.; Clayton, D., et al. Cultured colonic epithelial cells express pattern recognition receptors. In Proceedings 22nd ACVIM Forum 853.2004.

Weng, X. H.; Beyenbach, K. W.; Quaroni, A. Cultured monolayers of the dog jejunum with the structural and functional properties resembling the normal epithelium. Am. J. Physiol. Gastrointest. Liver Physiol. 288:G705-G717.2005.

Wong, M. H. Regulation of intestinal stem cells. J. Investig. Dermatol. Symp. Proc. 9:224-228.2004. 